\title{
Administração do Desenvolvimento na perspectiva Guerreirista: conceitos, contribuições e implicações
}

\author{
Development Administration in warmongering perspective: concepts, contributions and \\ implications
}

\author{
Elinaldo L. Santos ${ }^{1}$ \\ Universidade Estadual do Sudoeste da Bahia, Departamento de Ciências Sociais Aplicadas, Vitória da Conquista - BA, Brasil \\ Reginaldo Souza Santos ${ }^{2}$ \\ Universidade Federal da Bahia, Departamento de Finanças e Políticas Públicas, Salvador - BA, Brasil \\ Vitor Braga ${ }^{3}$ \\ Escola Superior de Tecnologia e Gestão de Felgueiras, Instituto Politécnico do Porto, Portugal
}

\begin{abstract}
Resumo
Percebe-se, hoje, um interesse, por parte dos pesquisadores da área dos Estudos Críticos em Administração (ECA) e dos Estudos Críticos em Desenvolvimento (ECD), em incluir o fenômeno da gestão do desenvolvimento nas suas investigações. Entretanto, constata-se que na década de 1960 já havia uma preocupação, por parte de Guerreiro Ramos, em relacionar o fenômeno da gestão com o do desenvolvimento das nações. Neste artigo, revisita-se o pensamento de Alberto Guerreiro Ramos, de modo a verificar as contribuições desse teórico para o campo da Administração do Desenvolvimento. Trata-se de um estudo exploratório de natureza bibliográfica das obras nas quais o autor, direta ou indiretamente, versou sobre a temática da gestão do desenvolvimento. O resultado das análises revela que alguns conceitos centrais, como fato administrativo, racionalidade substantiva, homem parentético e sociedade multicêntrica, são fundamentais para a compreensão da Administração do Desenvolvimento, como campo que se propõe a estudar a gestão das relações sociais de produção, distribuição e consumo dos países, regiões, lugares e/ou organizações.
\end{abstract}

Palavra-chave: Administração do Desenvolvimento. Guerreiro Ramos. Sociedade.

Artigo recebido em 24 de janeiro de 2014 e aceito para publicação em 12 de setembro de 2014.

DOI: http://dx.doi.org/10.1590/1679-395115511

1 Doutor em Administração pela Escola de Administração da Universidade Federal da Bahia (EAUFBA), em Cotutela com a Universidade Trás-os-Montes e Alto Douro (UTAD-Portugal); Professor do Departamento de Ciências Sociais Aplicadas da Universidade Estadual do Sudoeste da Bahia (UESB); Coordenador do Grupo Estudo e Pesquisa em Administração Política do Desenvolvimento (GPAP). Endereço: UESB/DCSA, Estrada do Bem Querer, km 4, CEP: 45083-900, Vitória da Conquista - BA, Brasil. E-mail: elinaldouesb@gmail.com

2 Pós-doutor em Economia pela Universidade Técnica de Lisboa (UTL/ISEG); Doutor em Economia pela Universidade Estadual de Campinas (Unicamp); Professor Titular do Programa de Pós-graduação da Escola de Administração da Universidade Federal da Bahia (NPGA/EAUFBA); Coordenador da Rede de Pesquisa em Administração Política (RPAP). Endereço: UFBA, Av. Reitor Miguel Calmon, Vale do Canela, CEP 40110-903, Salvador - BA, Brasil. E-mail: rsouza@ufba.br

${ }^{3}$ Doutor em Business Economics. Middlesex University Business School, Inglaterra; Professor Coordenador do Curso de Ciências Empresariais da Escola Superior de Tecnologia e Gestão de Felgueiras (ESTGF) do Instituto Politécnico de Porto (IPP); Coordenador da Unidade Técnico-Científica da ESTGF; Coordenador do Mestrado em Internacionalização de Empresas da ESTGF. Investigador efetivo do CIICESI e do CETRAD. Endereço: Rua do Curral, Apt. 205, CEP 4610-156, Felgueiras, Portugal. E-mail: vbraga@eu.ipp.pt 


\begin{abstract}
Currently, the Critical Studies in Administration (ECA - Estudos Críticos em Administração) and the Critical Studies in Development (ECD - Estudos Críticos em Desenvolvimento) show a clear concern in including the phenomenon of development management in their researches. However, it is clear that, in the 1960s, there was already a concern by Guerreiro Ramos to relate the phenomenon of management with the development of nations. Therefore, this study aims to revisit the thought of Alberto Guerreiro Ramos, in a way to explore his theoretical contributions to the field of Development Administration. This is an exploratory study of the author's bibliographical contribution, in which he has analyzed the development management, direct or indirectly. The result of the analysis reveals that some important concepts as the administrative fact, substantive reasoning, parenthetical man and multicenter society are fundamental issues to understand the Development Administration as a discipline aiming to study the management of social relations of production, distribution and consumption of countries, regions, places or organizations.
\end{abstract}

Keywords: Development Administration. Guerreiro Ramos. Society.

\title{
Introdução
}

A Administração do Desenvolvimento é um campo de estudo da Administração voltado para a análise da gestão das relações sociais de produção, distribuição e consumo da sociedade (SANTOS e SANTANA, 2010). Ela se diferencia dos Estudos Organizacionais (EOs) por dois motivos: primeiro, por não ter como objeto de estudo a organização, mas a gestão; segundo, porque, ao passo que os Estudos Organizacionais centram-se na investigação de organizações modernas ou mesmo pós-modernas, a Administração do Desenvolvimento, por sua vez, prioriza o estudo de sociedades, países, regiões, organizações, que, muitas vezes, encontram-se aquém da modernidade (COOKE, 2004; SANTOS, 2004; GULRAJANI, 2009). Possui origem na ortodoxia do pensamento administrativo no mundo pós-guerra, precisamente nos planos de recuperação econômica - Plano Marshall, Plano Colombo, Aliança para o Progresso - e no desejo dos países ricos em auxiliar tecnicamente os países menos desenvolvidos, com programas de ajuda mútua.

Com o advento dos Estudos Organizacionais (EOs), o campo da Administração foi, aos poucos, redimensionando a sua agenda investigativa para temas mais específicos, como o comportamento organizacional e a teoria das organizações, deixando, com isso, espaços para que outros campos de conhecimento (Economia, Sociologia, Geografia e Antropologia) se dedicassem aos estudos de questões mais amplas como o da gestão do desenvolvimento (CUNHA, 2000). Porém, quase 40 anos após esse redimensionamento epistemológico, percebe-se um esforço, por parte dos pesquisadores, da área dos Estudos Críticos em Administração (ECA) e dos Estudos Críticos em Desenvolvimento (ECD), em retomar as questões intrínsecas do desenvolvimento, precisamente no que refere à sua gestão (COOKE, 2004; DAR e COOKE, 2008; ESCOBAR, 2008; GULRAJANI, 2009; MISOCZKY, 2011; COOKE e FARIA, 2013; MISOCZKY e BOHN, 2013). Entretanto, constata-se, já nas décadas de 1960, 1970 e 1980, o pioneirismo de Alberto Guerreiro Ramos nessas questões ao refletir, na ocasião, sobre o futuro e a função social da Administração do Desenvolvimento.

Todavia, durante muito tempo, a contribuição intelectual desse baiano, sociólogo, filósofo, político, de ancestralidade africana foi esquecida no Brasil. Somente depois de ter conquistado uma carreira acadêmica em universidades como a do Sul da Califórnia, de Yale e Toronto; ter recebido, por três vezes, o prêmio Teaching Excellence Award of the School of Public Administration e uma vez o prêmio Teaching Execellence Award of the University Associates Award, com seu último trabalho (The new science of organization - an reconceptualization of the wealtb of nations), publicado pela Universidade de Toronto, em 1981; e ter ganhado o prêmio Pib Kappa Book Award, como a melhor publicação do ano na área, é que a academia brasileira passa a reconhecê-lo como um dos seus mais importantes pensadores, tornando-se, assim, objeto de tese e de investigações de muitos pesquisadores (AZEVEDO, 2006). 
Diante disso, no presente ensaio o objetivo é revisitar o pensamento de Guerreiro Ramos, de modo a verificar as contribuições desse teórico para o campo da Administração do Desenvolvimento. Para alcançar este objetivo optou-se por um estudo bibliográfico, fundamentado no método historiográfico, denominado 'história dos conceitos' (Begriffgeschichte), de autoria do historiador alemão Reinhar Koselleck (2006). A história conceitual é um tipo de estudo da linguagem, cuja unidade de análise constitui-se de uma espécie de signo linguístico em particular: o conceito (VIZEU e MATITZ, 2011). De modo geral, a história dos conceitos põe em evidência a estratificação dos significados de um mesmo conceito em épocas diferentes; trabalha segundo a premissa teórica da obrigatoriedade de confrontar e medir permanência e alteração. Uma vez cunhado, um conceito passa a conter, em si, do ponto de vista exclusivamente linguístico, a possibilidade de ser empregado de maneira generalizante, de construir tipos ou permitir ângulos de vista para comparação (KOSELLECK, 2006). No caso específico deste estudo, tomou-se como objeto de análise a produção científica de Guerreiro Ramos, publicada nas décadas de 1960, 1970 e 1980, que, direta ou indiretamente, tiveram como abordagem a temática da gestão do desenvolvimento. O estudo foi desenvolvido em três fases. A primeira consistiu numa leitura prévia do material, possibilitando o conhecimento da estrutura narrativa, linguística, semiótica, histórica e ideológica dos manuscritos. A segunda consistiu na escolha das categorias conceituais - fato administrativo, racionalidade substantiva, homem parentético e sociedade multicêntrica com vistas à análise do sentido dado pelo autor. A terceira constitui-se de verificação das contribuições e implicações dos conceitos para o campo da Administração do Desenvolvimento. Para tanto, foram considerados os trabalhos Administração e Estratégia do Desenvolvimento: elementos de uma sociologia espacial da administração, publicado originalmente em 1966 (RAMOS, 1983); A Nova Ciência das Organizações: uma reconceituação da riqueza das nações, publicado em 1981 (RAMOS, 1989); como também, os artigos: "Modernização em Nova Perspectiva: em busca do modelo da possibilidade, publicado em 1967 (RAMOS, 2009); "A nova ignorância e o futuro da Administração Pública na América Latina" (RAMOS, 1970); e "Models of man and administrative theory" (RAMOS, 1972). Contudo não podemos esgotar a contribuição de Guerreiro Ramos para a Administração do Desenvolvimento apenas nessas obras, mesmo porque, seus estudos extrapolam as fronteiras do conhecimento das ciências administrativas e organizacionais e servem de parâmetro às ciências sociais como um todo.

O ensaio está estruturado em quatro seções depois desta introdução. Na primeira, explora-se o conceito de ciência administrativa concebido pelo autor, relacionando-o com o campo da Administração do Desenvolvimento; na segunda, evidencia-se a visão que Guerreiro Ramos tem sobre a Administração do Desenvolvimento. Esta se apresenta como um campo prático e teórico, por meio do qual se pode observar, descrever e explicar as contradições existentes no desenvolvimento do sistema-mundo. Na terceira, verificam-se as contribuições do autor para a compreensão da Administração do Desenvolvimento, focandose nas análises de três conceitos centrais - racionalidade substantiva, homem parentético e sociedade multicêntrica; na quarta seção, apresenta-se uma reflexão sobre o futuro dessa disciplina como campo de conhecimento dentro da administração.

\section{Administração como Fato Social}

Já no primeiro capítulo de Administração e Estratégia do Desenvolvimento: elementos de uma sociologia especial da administração, Ramos (1983) esboça os fundamentos de sua teoria geral da administração. Nesse capítulo, toca em questões controversas dentro do campo da Administração, tais como: o que se produz, a qualidade da sua produção científica e se existe ou não uma ciência da administração. Na hipótese de existir, qual seria a maneira de conceber essa ciência? Assim, lamenta o fato de, até então, a Sociologia não ter dado a devida atenção ao fenômeno administrativo, uma vez que, para ele, a administração também tem a sua sociologia espacial ou sociologia administrativa, tal como a sociologia jurídica, a religiosa, a artística ou a econômica. Em suas palavras, “[...] é surpreendente que, até agora, os sociólogos, de modo geral, tenham descurado de formulá-la, em seus termos específicos, como já o fizeram para aqueles outros fenômenos [jurídicos, religiosos, econômicos, entre outros]" (RAMOS, 1983, p. 2). Diante disso, o autor entende a 
Administração como uma realidade saliente da vida, que conclama por uma sociologia espacial e reconhece que poucos especialistas em Sociologia têm escolhido a Administração como seu campo de interesse. Com isso, dedica boa parte de sua vida intelectual aos estudos da ciência administrativa e organizacional, contribuindo, assim, para a elaboração de uma sociologia espacial da administração tal como revisou na segunda edição do seu livro Administração e Estratégia do Desenvolvimento, uma teoria geral da administração. Para ele, "[...] essa disciplina é a parte da sociologia geral que estuda a realidade social da administração, suas expressões exteriormente observáveis como fato, sistema e ação, sua tipologia qualitativa historicamente condicionada, seus elementos componentes - aestruturais, estruturais e estruturantes" (RAMOS, 1983, p. 3).

Assim, ele classifica o campo da Administração como parte integrante da Sociologia e se inspira na sociologia clássica, sobretudo de Émile Durkheim, para demonstrar a relação entre o fato social e o fato administrativo. Em suas análises, expõe a tese de que o estudo científico do fato e do sistema administrativo é necessariamente pluridimensional, uma vez que o fenômeno administrativo decorre das relações históricas e sociais e, em virtude disso, não pode ser considerado apenas como simples fenômeno da vida social, tal como imaginam os pensadores ortodoxos da ciência da Administração. $\mathrm{O}$ fato administrativo é visto por Guerreiro Ramos como um complexo de elementos que mantêm relações entre si, resultante e condicionante da ação ou omissão de diferentes pessoas, escalonadas em diferentes níveis de decisão, no desempenho de funções que limitam e orientam atividades humanas associadas, tendo em vista, objetivos sistematicamente estabelecidos (RAMOS, 1983, p. 7). Por esse conceito, fica evidente que a ação administrativa decorre de estrutura hierárquica orientada para alcançar objetivos racionalmente definidos, cuja finalidade consiste em promover o bem-estar da vida humana associada. Isto revela, também, que, quando praticada em uma sociedade multicêntrica, a ação administrativa requer tomada de decisão, comunicação, negociação, eficiência, eficácia e, além disso, efetividade, reciprocidade e sustentabilidade.

Essa definição ajuda a esclarecer que diante de um fato administrativo encontram-se também fatos políticos, jurídicos, econômicos e tecnológicos, dado que aquele surge do contexto histórico-social, portanto, está sujeito às dimensões de tempo, espaço e cultura. Ramos compreende o fato administrativo como um fenômeno "da, com e para" a sociedade, diferentemente dos estudiosos ortodoxos, que pensam o fato administrativo como um processo (diagnóstico-prescrição-solução), fundamentado numa lógica tecnicista e mercadológica. O conceito de fato administrativo em Ramos (1983) concede à Administração o status de uma ciência capaz de observar, descrever e explicar as contradições existentes nas relações sociais de produção, distribuição e consumo do mundo capitalista. .

Neste artigo, entende-se que o conceito de administração proposto por Guerreiro Ramos avança na medida em que o fato administrativo é reconhecido como um fenômeno histórico-social, cuja finalidade é promover o bem-estar da vida humana associada, superando, com isso, o conceito prescritivo do pensamento ortodoxo de Taylor e Fayol. Isso, por sua vez, ajuda a compreender, por meio do campo da Administração do Desenvolvimento, que a gestão do desenvolvimento não se restringe ao saber tecnicista, conforme imaginam os teóricos da escola ortodoxa ao visualizarem o desenvolvimento como algo pertencente aos especialistas. A Administração do Desenvolvimento tende a ser um processo que opera, pelo menos, em três níveis: indivíduo, organização e sociedade, bem como em várias dimensões: econômicas, sociais, políticas, ambientais e/ou humanas, tal como sinaliza Cooke (2008), e não apenas como um conjunto de ferramentas e técnicas gerenciais dos países ditos avançados para países em desenvolvimento.

\section{Administração do Desenvolvimento na Perspectiva de Guerreiro Ramos}

No artigo intitulado "A nova ignorância e o futuro da Administração Pública na América Latina" (RAMOS, 1970), o autor faz uma análise dos fatores que limitam o campo da Administração e, consequentemente, o campo da Administração do Desenvolvimento. Chama a atenção não só da ciência da Administração, como também das Ciências Sociais, para a ausência de investigações científicas capazes de revelar as contradições 
do sistema-mundo, principalmente como categoria de análise e objeto ético. Diante disso, reconhece que "[...] se ainda há grandes disparidades no padrão de vida de diferentes povos, hão-de ser antes um produto institucional do que o resultado de uma real escassez de meios" (RAMOS, 1970, p. 12).

Dessa forma, Ramos busca evidenciar o desequilíbrio existente entre países do centro e da periferia e critica a visão dos economistas clássicos, que desconsideram a ética nos negócios econômicos, e dos neoclássicos, por verem o problema da desigualdade na escassez de recursos e não nas decisões institucionais. Assim, a riqueza e a pobreza ganham novo sentido, tornam-se essencialmente obras do homem. $\mathrm{O}$ autor prossegue, afirmando que "[...] é possível criar a riqueza por meio de uma administração adequada, isto é, mediante conhecimento aplicado, [...] entretanto, é preciso ter outra visão do mundo" (RAMOS, 1970, p. 12). Para isso, seria necessário que os cientistas sociais incluíssem o "sistema-mundo" nas investigações dos seus campos de conhecimento, uma vez que, até aquele momento, a ênfase havia sido dada apenas ao elemento "Estado-nação".

A ausência, na literatura científica, de um modelo analítico de alocação de recursos para o sistema-mundo provoca, em Ramos (1970), a necessidade de destacar a importância de uma disciplina dentro do campo das Ciências Sociais capaz de observar, descrever e explicar as contradições existentes no desenvolvimento do sistema-mundo, o que, para o autor, seria possível na Administração do Desenvolvimento. Para isso, entende ser necessário o aparecimento de um novo Adam Smith, cuja tarefa seria escrever não "a riqueza das nações", mas "a riqueza do mundo". Em suas palavras:

Com efeito, se faz sentido falar em administração do desenvolvimento como disciplina e profissão, sua missão será estudar questões e problemas de desenvolvimento mundial, quais as condições e limites de tal desenvolvimento, qual o enfoque a adotar, como promover esse desenvolvimento. Essa missão exige um esforço de criatividade conceitual, engenhosidade na formulação de estratégias adequadas para a alocação de recursos, e, finalmente não menos importante, a especificação dos objetivos a serem atingidos. (RAMOS, 1970, p. 13).

Para melhor entender a proposta da Administração do Desenvolvimento de Ramos, torna-se necessário considerar que estamos nos referindo a um interpretativista crítico, para quem o sentido das coisas não está necessariamente no fenômeno, mas na atribuição de sentido que o sujeito lhe dá por meio do significado conferido pela razão. Para ele, existem pelo menos três significados para o construto "desenvolvimento" no campo da Administração:

- Desenvolvimento Utópico: baseado em valores centrados na caridade e fraternidade. Isso ocorre quando algumas pessoas (líderes religiosos, visionários, artistas, idealistas) desejam um mundo melhor que o atual e apelam para a generosidade dos detentores de recursos, porém, não produzem efeitos eficazes;

- Desenvolvimento Sectário: com base ideológica doutrinária, cujos poderes hegemônicos concebem o mundo ideal conforme suas próprias conveniências. Isso ocorre em situações em que se vivencia demarcação de território, como Socialismo versus Capitalismo, Primeiro Mundo versus Terceiro Mundo, avançado versus atrasado, crescimento versus conservação etc. Essa concepção limita a capacidade humana, podendo levar a um estágio de alienação;

- Desenvolvimento das Possibilidades: ocorre na fronteira entre o determinismo e a liberdade. Não existe um único caminho, nem tampouco todas as possibilidades, e escolher uma possibilidade em determinada situação é escolher dentro de certos limites. O desenvolvimento, nesse caso, surge de fatores limitantes e inovadores da natureza humana. Limites e inovações se entrelaçam para promover outra situação (RAMOS, 1970). 
Ramos considera o Desenvolvimento das Possibilidades o mais apropriado para a consolidação do campo da Administração do Desenvolvimento. O "desenvolvimento" em Ramos tem um sentido paradoxal, uma vez que ele considera que desenvolvimento ocorre por meio das possibilidades objetivas, cuja escolha ou o exercício da possibilidade humana vai além do indivíduo e compreende a coletividade, como também a construção de uma realidade que se encontra entre o que deve ser e o que poderá ser. Para ele, "[...] as possibilidades contidas na situação imediata em que se encontra o sujeito são sempre mais numerosas do que as que percebe e as que acontecem" (RAMOS, 1983, p. 163). Em função disso, defende a ideia de que as possibilidades objetivas nunca serão as mesmas de outra sociedade. Em outras palavras, não deveremos seguir, necessariamente, os mesmos percursos dos países centrais pois, sempre é possível encontrar um percurso mais apropriado e condizente com a nossa realidade. Sobre isso, coaduna-se com Victor Thompson, quando em suas análises descreve os fatores críticos da Administração do Desenvolvimento:

A prática e os princípios administrativos do Ocidente derivam de uma preocupação com controle, e por isso têm pouco valor para a administração do desenvolvimento em países subdesenvolvidos, onde há necessidade de uma administração adaptativa, capaz de incorporar constantes mudanças. As pesquisas e teorias das ciências do comportamento permitem deduzir princípios para uma administração adaptativa os quais devem tornar-se objetivos dos administradores do desenvolvimento. Como exemplos de tais princípios, vale mencionar: clima de inovação; operacionalização e compartilhamento de objetivos; combinação de planejamento (pensar) e ação (fazer); minimização de provincialismos; difusão de influência; maior tolerância para com a independência; evitar a buropatologia. (THOMPSON, 1968 apud RAMOS, 1970, p. 21).

Na visão de Ramos, não podemos fazer da Administração do Desenvolvimento um objeto de exportação dos países detentores de conhecimento para países sem conhecimento apropriado. Isso é uma forma de controle que não legitima a sua ação. Antes de tudo, é preciso analisar o contexto, não só do espaço-local, mas, sobretudo, do espaço-mundo. Não se pode falar do desenvolvimento das nações sem a contextualização das discrepâncias do espaço-mundo, já que "[...] o objetivo do desenvolvimento, tanto nas nações do centro quanto nas periféricas, é o bem-estar de todos os cidadãos" (RAMOS, 1970, p. 22). Esse entendimento é compartilhado por outros teóricos que também estudam a gestão do desenvolvimento capitalista, sobretudo, pelos teóricos da teoria da dependência e da teoria do sistema-mundo (ARRIGHI, 2003; 2008; DOS SANTOS, 2002; WALLERSTEIN, 2000). De modo geral, esses pensadores defendem a tese de que as políticas de desenvolvimento sejam formuladas para promover a distribuição da riqueza e não para a concentração desta em algumas poucas mãos.

Em A Nova Ciência das Organizações: uma (re)conceituação da riqueza das nações (RAMOS, 1989), ao apresentar o paradigma paraeconômico como uma estrutura de uma teoria política substantiva de alocação de recursos, o autor deixa claro que a Administração só conseguirá cumprir sua finalidade maior, ou seja, o bem-estar social, se os indivíduos, as instituições e os governos se libertarem dos equívocos conceituais inerentes aos modelos alocativos de mercado. Porém, para que isso de fato ocorra, é preciso reconceituar a riqueza das nações, revendo seus antigos pressupostos:

1. Os critérios para a avaliação do desenvolvimento de uma nação são essencialmente os mesmos que dizem respeito às atividades que constituem a dinâmica do mercado [...] simplesmente indicadores quantitativos;

2. Há uma presunção de que a natureza humana define como o conjunto de qualificações e de disposições que caracterizam o indivíduo como um detentor de emprego e como um comprador insaciável;

3. A eficácia da organização e das instituições em geral é mensurada do ponto de vista de sua contribuição direta ou indireta para a maximização das atividades do mercado [...] sociedade unidimensional centrada no mercado. (RAMOS, 1989, p. 181-182). 
'(Re)conceituar' a riqueza das nações, na perspectiva de Ramos, significa rever o atual modelo de alocação de recursos proposto pela economia política e praticado pela sociedade mercantilista. A economia de base industrial, seja ela capitalista ou socialista, pressupõe que os recursos são escassos e as necessidades são ilimitadas, o que, conforme o autor, é um erro central e trágico. Na realidade, é fato que numerosos recursos físicos e naturais, necessários à continuidade da operação do mercado, são de natureza não renovável e podem exaurir-se em longo prazo. Contudo existem outras dimensões de recursos - ecológicas e psíquicas não incluídas nos recursos produtivos da sociedade de mercado. Por essa razão, visualiza-se um sistema de alocação de recursos dual, isto é, "[...] coexistência de sistemas de orientação mutuária, nos quais os respectivos membros produzem para si mesmos uma grande parte dos bens e serviços que diretamente consomem, e de sistemas orientados para o lucro em que os membros são, essencialmente, detentores de empregos" (RAMOS, 1983, p. 188). Para isso acontecer, é preciso que o sistema de mercado seja politicamente regulado, a fim de não prejudicar as bases econômicas de orientação mutuária e comunitária, socialmente reconhecidas, como associações, cooperativas, redes solidárias, comunidades tradicionais, entre outras, que não são guiadas pela lógica do individualismo, da competição e da lucratividade. A Administração do Desenvolvimento, nessa perspectiva, apresenta-se como um modelo de alocação de recursos econômicos e não econômicos em sistemas sociais de natureza multicêntrica. Ela incorpora as várias possibilidades de organização da produção, da distribuição e do consumo, dado que não se restringe apenas ao sistema de troca mercantil, mas, também, a outros sistemas, como o da reciprocidade, da isonomia e o da fenonomia. Com isso, busca-se satisfazer as necessidades individuais e coletivas da sociedade.

Do que aqui se depreende, a Administração do Desenvolvimento, concebida por Guerreiro Ramos, avança na medida em que incorpora outras possibilidades de organização da produção para além do mercado, porém, limita-se quando não traz em si o reconhecimento ou o aprofundamento das causas históricas das desigualdades entre sociedades, como se observa em alguns estudiosos do desenvolvimento capitalista (DOS SANTOS, 2002; ESCOBAR, 1995; 2008; WALLERSTEIN, 2000). Além disso, não avança na discussão sobre a emancipação econômica das sociedades periféricas, como demonstram alguns investigadores dos estudos críticos (MISOCZKY, 2011; WANDERLEY e FARIA, 2012). Em razão disso, entende-se que se trata de uma proposta de natureza reformista do modelo hegemônico de alocação de recursos. Para o aprofundamento dessa discussão, serão analisados, na seção seguinte, três conceitos centrais do pensamento de Guerreiro Ramos - razão substantiva, homem parentético e sociedade multicêntrica - com o intuito de perceber as contribuições desses conceitos para o campo da Administração do Desenvolvimento.

\section{Contribuições para Administração do Desenvolvimento}

Do ponto de vista epistemológico, a contribuição de Ramos para a Administração do Desenvolvimento encontra-se esboçada no seu livro Administração e Estratégia do Desenvolvimento: elementos de uma sociologia especial da administração (RAMOS, 1983), no qual, mediante exame de cinco categorias analíticas (administração, racionalidade, burocracia, estratégia e formalismo), elabora conceitos para a compreensão do desenvolvimento da sociedade brasileira. Porém, alguns dos conceitos foram depois mais bem clarificados com a publicação de A Nova Ciência das Organizações: uma reconceituação da riqueza das nações (RAMOS, 1989), a exemplo do conceito de paradigma paraeconômico e de outros que foram abordados em trabalhos apresentados em congressos e publicados em artigos científicos. Contudo o próprio Guerreiro afirma que "[...] não foi desenvolvida ainda uma enunciação sistemática dessa teoria [paraeconomia], embora se encontrem disponíveis contribuições fragmentárias para sua elaboração" (RAMOS, 1989, p. 177).

Essa declaração permite deduzir que a agenda de estudo para a sistematização de uma teoria geral da administração provavelmente foi interrompida em virtude do seu falecimento repentino, em 1982, um ano após a publicação de A Nova Ciência das Organizações. Diante disso, supõe-se que Guerreiro Ramos ainda tinha em mente uma proposta mais elaborada para o seu conceito de paradigma paraeconômico, que, além de 
ser apresentado como um método de análise e planejamento de sistemas sociais, era considerado por ele uma estrutura de uma teoria política substantiva de desenvolvimento, em contraponto com a teoria política de desenvolvimento da economia. Em suas palavras: "Contudo, a paraeconomia pode ser entendida também como proporcionadora da estrutura de uma teoria política substantiva de alocação de recursos e de relacionamentos funcionais entre enclaves sociais, necessários à estimulação qualitativa da vida social dos cidadãos" (RAMOS, 1989, p. 177).

Para avançar no entendimento das contribuições de Ramos sobre uma teoria política substantiva do desenvolvimento, é preciso considerar a sua visão de mundo, como também a sua concepção filosófica de ciência exposta no método da redução sociológica. Muitos pressupostos, formulados no conjunto de sua obra, chamam a atenção para o fato de serem avançados para a época, já que boa parte dos argumentos que o autor utilizava para validar seus pressupostos só recentemente vêm sendo discutidos pela comunidade científica. No geral, podemos agrupar tais pressupostos em três concepções analíticas: i) racionalidade substantiva; ii) homem parentético; e iii) sociedade multicêntrica. Uma descrição mais aprofundada dessas categorias analíticas é apresentada nas subseções que se seguem, tendo em vista que, de alguma forma, estão presentes no conceito de Administração do Desenvolvimento imaginado por Guerreiro Ramos.

\section{A racionalidade substantiva}

A preocupação de Guerreiro Ramos em rever o sentido da racionalidade nas organizações teve início na primeira edição de Administração e Estratégia do Desenvolvimento: elementos de uma sociologia especial da administração (RAMOS, 1983), com a elaboração do conceito de ação administrativa ${ }^{4}$. Nesse trabalho, o sociólogo baiano retoma os estudos de Max Weber, Karl Mannheim, Chester Barnard, Herbet Simon, Amitai Etzioni e Dwight Waldo para ressignificar o sentido da racionalidade das organizações até aquele momento. Porém, é com The new science of organization - an reconceptualization of the wealth of nations, publicado pela Universidade de Toronto, que a ressignificação da racionalidade nas organizações ganha notoriedade.

Nesse trabalho, Ramos (1983) afirma que a teoria da organização, tal como prevalecia até então, era ingênua por se basear na racionalidade instrumental inerente à ciência social, dominante no Ocidente. Para ele, a ingenuidade tem sido o fato que explica o sucesso prático da racionalidade instrumental; entretanto, para que isso aconteça, é preciso fingir que a ingenuidade é o certo, ao passo que a sofisticação teórica é o errado. A ingenuidade dos cientistas sociais está na crença de desenvolver uma ciência da sociedade com base na racionalidade das ciências naturais. $\mathrm{O}$ autor argumenta ainda que, nos últimos três séculos, essa crença inspirou toda uma geração de teóricos e pensadores do mundo ocidental, principalmente os economistas. Estes, seguindo as orientações de Adam Smith, eliminaram a ética da filosofia clássica de Aristóteles das relações econômicas e introduziram a razão como um cálculo utilitário de consequências para melhor prever o comportamento humano em sociedade. Nessa perspectiva, algumas características da natureza humana, como instintos, paixões, interesses, motivações, foram relegadas nas análises econômicas.

Essa visão fundamentalista dos economistas instigou Ramos a retomar o sentido clássico da razão e rever o significado da racionalidade nas organizações. Em suas análises para a formulação de uma teoria das organizações, Ramos faz uma crítica aberta à ciência administrativa quando afirma que a mesma não desenvolveu a capacidade analítica necessária à crítica de seus alicerces teóricos; ao contrário, apropriou-se de conceitos exteriores, principalmente do campo da economia política utilitarista. Por essa razão, tornou-se periférica perante as Ciências Sociais, e, diante disso, o autor aponta como pontos cegos quatro características da teoria organizacional tradicional:

\footnotetext{
${ }^{4}$ Guerreiro Ramos (1983) chama "ação administrativa" a toda modalidade de ação social que transita entre a (ir)racionalidade funcional e a (ir)racionalidade substantiva, bem como entre a ética da responsabilidade e a ética do valor absoluto.

${ }^{5}$ Entendida como força ativa na psique humana que habilita o indivíduo a distinguir entre o bem e o mal, entre o conhecimento falso e o verdadeiro e, assim, a ordenar sua vida pessoal e social (RAMOS, 1989, p. 2).
} 
1. O conceito de racionalidade predominante na vigente teoria organizacional parece afetado por fortes implicações ideológicas. Conduz à identificação do comportamento econômico como constituinte da totalidade da natureza humana;

2. A presente teoria da organização não se distingue, sistematicamente, entre o significado substantivo e o significado formal da organização. A organização econômica formal é uma inovação institucional recente do mundo capitalista [...]. A organização econômica formal não pode ser considerada um paradigma [...] devem ser estudadas todas as formas de organizações passadas, presentes e emergentes;

3. A presente teoria da organização não tem clara compreensão do papel da interação simbólica, no conjunto das relações interpessoais;

4. A presente teoria da organização apoia-se numa visão mecanomórfica da atividade produtiva do homem. (RAMOS, 1989, p. 121).

Para que haja um contraponto à teoria da razão instrumental da administração, Ramos propõe um conjunto de pressupostos a fim de construir uma teoria da razão substantiva da administração necessária à reformulação da ciência organizacional tradicional. Com base nesses pressupostos questiona, de alguma forma, a sustentação do pensamento ortodoxo da economia política, bem como da ciência da administração. Estes pressupostos são:

1. O homem tem diferentes tipos de necessidades cuja satisfação requer múltiplos tipos de cenários sociais;

2. O sistema de mercado só atende a limitadas necessidades humanas em que se espera do indivíduo um desempenho consistente com regras de comunicação operacional formal ou critérios intencionais e instrumentais, agindo como um ser trabalhador;

3. Diferentes categorias de tempo e espaço vital correspondem a tipos diferentes de cenários organizacionais;

4. Diferentes sistemas cognitivos pertencem a diferentes cenários organizacionais;

5. Diferentes cenários sociais requerem enclaves distintos no contexto geral da tessitura da sociedade, com vínculos que os tornam inter-relacionados. (RAMOS, 1989, p. 136).

Nessa perspectiva, Ramos entende que a razão humana não deve ser vista apenas pelo prisma do cálculo utilitário ou pelo êxito econômico, nem se deve sequer acreditar que a razão é produto das leis egocêntricas do mercado. Este é apenas uma dimensão da vida social e não pode ser tido como sinônimo de sociedade. Sua tese é de que "[...] a ação administrativa é pautada entre a racionalidade funcional e a substantiva" (RAMOS, 1983, p. 49). A racionalidade substantiva é guiada pela busca da satisfação humana mediante equilíbrio dos interesses individuais e do coletivo. Sua ação decorre não da razão pura, mas dos sentimentos humanos, como instintos, paixões e interesses. Ramos (1989) chama a atenção para o fato de a ciência organizacional ortodoxa não ter se posicionado claramente em defesa da ação administrativa como uma dimensão que transita entre a racionalidade funcional e a substantiva, limitando-se apenas a explicar a importância da racionalidade funcional no seu modelo de tomada de decisão administrativa.

Assim, reconhece-se que a crítica ao uso exacerbado da razão instrumental por parte da economia política e seguidores, bem como a retomada da discussão sobre a razão substantiva no campo das ciências sociais, em específico no campo da ciência da Administração, constituem uma importante contribuição para o campo da Administração do Desenvolvimento, uma vez que desmistifica a tese de que a gestão do desenvolvimento só é viável em condições de racionalidade instrumental extrema. Como já fora exposto anteriormente, a 
Administração do Desenvolvimento decorre das relações sociais estabelecidas entre indivíduos, organizações e sociedade, e essas emanam tanto das ações racionais instrumentais quanto das ações racionais subjetivas. Porém, deve-se destacar que essa consciência relativizada não rompe com a tradição do movimento iluminista de colocar o homem como o centro das questões, dado que o desenvolvimento requer um diálogo entre homem, sociedade e natureza, que não é aprofundado em Guerreiro Ramos.

\section{O homem parentético}

A Administração do Desenvolvimento, na perspectiva de Guerreiro Ramos, exige uma abordagem antropológica para além do homem organizacional, uma vez que este representa o modelo de homem da sociedade industrial, incompatível, portanto, com uma sociedade multicêntrica. O homem organizacional é representado por duas categorias: o homem operacional - calculista e motivado por recompensas materiais (homo economicus, homo sociologicus, homo politicus) - e o homem reativo ou comportamental - aquele que se ajusta ao contexto, conforme suas necessidades individuais. Todavia essas categorias são, para Ramos, insuficientes para a aplicabilidade dos seus conceitos de administração, de razão humana e de sociedade multicêntrica. Em razão disso, propõe em Models of man and administrative theory (RAMOS, 1972) uma nova concepção da natureza humana para além do homem organizacional. Apresenta, nesse trabalho, a ascensão do homem parentético, um ser autônomo diante dos fatos, que possui uma consciência crítica e valores não concebidos dentro do campo da racionalidade utilitária, como aqueles que existem nos demais modelos. $\mathrm{O}$ homem parentético é o reflexo das novas circunstâncias sociais, sejam essas econômicas, políticas e/ou tecnológicas de uma sociedade pós-industrial. Faria (2009) descreve as características do homem parentético proposto por Ramos da seguinte forma:

1. Não se empenha em excesso para ser bem sucedido segundo padrões convencionais, pois tem grande senso de individualidade e uma forte compulsão para encontrar sentido para sua vida;

2. Não aceita padrões de desempenho sem um senso crítico, embora possa ser um grande realizador quando lhe forem atribuídas tarefas criativas;

3. Evita trabalhar apenas com o intuito de fugir à apatia ou à indiferença, pois o comportamento passivo ofende o seu senso de autoestima e autonomia;

4. Empenha-se para influenciar o ambiente, para retirar dele tanta satisfação quanto é capaz;

5. É ambivalente em relação à organização, mas de um modo qualitativo que decorre do seu entendimento de que as organizações têm que ser tratadas de acordo com seus próprios termos relativos, já que elas são limitadas por sua racionalidade funcional. (FARIA, 2009, p. 429).

Nas análises de Azevedo e Albernaz (2006, p. 14), o homem parentético (um ser de razão), ao exercer a afirmação do self, a liberdade, a autorrealização e a racionalidade substantiva, transcenderia o universo normativo das instituições modernas e adentraria numa sociedade pós-institucional, livre dos códigos de conduta e de ética pré-fabricadas. O homem parentético seria um 'ser épico', um ser que pode sempre formar, desenhar, constituir a si mesmo pela exploração do campo de possibilidades disponíveis a cada momento.

Esse modelo antropológico, em parte, está fundamentado no capítulo terceiro da obra A Nova Ciência das Organizações, denominado síndrome comportamentalista. Nele, Guerreiro Ramos faz uma distinção entre ação comportamental e ação parentética para destacar o reducionismo da teoria organizacional tradicional. Ele considera a ação comportamental como uma forma de conduta oportunista da vida social, de agir pela racionalidade funcional e pelas expectativas utilitaristas. Por sua vez, a ação parentética é própria de um agente (indivíduo, instituição e governo) consciente de suas finalidades intrínsecas; possuidor de uma ética de conduta e de uma razão suprema, capaz de deliberar sobre coisas. Em síntese: a ação parentética coloca a razão e a liberdade no centro da articulação do homem com o mundo (AZEVEDO e ALBERNAZ, 2006). 
Esse esclarecimento deixa nítido que o homem organizacional é um indivíduo limitado do ponto de vista de sua consciência crítica, porque age mediante comportamento condicionado, ao passo que o homem parentético exerce sua ação consciente dos fatos.

A síndrome comportamentalista é uma característica básica da sociedade industrial construída intencionalmente pelos adeptos da Teoria da Racionalidade Instrumental (TRI). Já a ação parentética é um traço da sociedade pós-industrial, fundamentado, sobretudo, na Teoria da Racionalidade Substantiva (TRS). O homem parentético, por sua vez, possui características tanto da racionalidade instrumental como da racionalidade substantiva, permitindo, com isso, suspender ou pôr "entre parênteses" as circunstâncias do mundo cotidiano, a fim de despertar no indivíduo uma capacidade analítica e crítica dos fatos. Com isso, espera-se que esse indivíduo consiga, pela sua capacidade psicológica, se separar de seu ambiente interno e externo para poder ver, julgar e agir.

Esse modelo de homem constitui um elemento essencial para a Administração do Desenvolvimento, uma vez que trata de um sujeito analítico, crítico e reflexivo, essencial a uma gestão do desenvolvimento na qual, de fato, existam relações sociais entre indivíduos, organizações e sociedade em espaços geográficos diversos (global, regional e/ou local). Entretanto é importante destacar que o homem parentético, segundo descreve o próprio Guerreiro Ramos, é uma categoria analítica da sociedade pós-industrial, portanto, bastante restrito, pois, a maioria das nações é composta de sociedades pré-industriais e industriais. Diante disso, entende-se que nem todas as sociedades industrializadas podem ser classificadas como desenvolvidas, essa associação é uma interpretação da sociedade ocidental moderna, dado que pela interpretação dos teóricos do pósdesenvolvimento e da pós-modernidade, essa visão de desenvolvimento seja um mito (ESCOBAR, 1995; 2008).

\section{A sociedade multicêntrica}

Ramos (1989) visualiza uma sociedade multidimensional, na qual o mercado é considerado um dos enclaves sociais, legítimo e necessário, mas limitado e regulado. Essa visão de sociedade é descrita pelo autor como paradigma paraeconômico. Nele, o homem é capaz de desempenhar diversas atividades da vida social (econômicas, culturais, religiosas, científicas, tecnológicas) sem perder a consciência da ação e dos fatos, uma vez que não se comporta como um ser passivo de uma realidade social dominada exclusivamente pelo mercado.

A sociedade multidimensional se contrapõe à sociedade unidimensional, em que só existe um tipo de socialização, aquela em que as ações humanas são guiadas pela racionalidade do mercado e agem como se tal racionalidade fosse supremo padrão normativo de todo o espectro de suas relações interpessoais. A sociedade unidimensional seria, em outras palavras, uma sociedade centrada no mercado, cujos critérios para alocações de recursos se dão pela relação custo-benefício e pela lucratividade; para tanto, utiliza-se a racionalidade funcional/ instrumental. Ramos desenvolve o conceito de paradigma paraeconômico como uma tentativa sistemática de superar a visão hegemônica da sociedade unidimensional. Nele os critérios de alocação de recursos não se dão apenas pela visão utilitária do homem operacional, nem tampouco pela visão ingênua do homem comportamental, mas, sim, pela ação do homem parentético, o qual, para alcançar a sua realização pessoal, precisa libertar-se totalmente da visão míope do mercado como único meio de alocação de recursos e de detenção de empregos.

De acordo com Ramos, é possível visualizar uma sociedade multidimensional ou multicêntrica quando se desenvolve um novo modelo de análise e planejamento de alocação de recursos, para além do modelo hegemônico proposto por Adam Smith e seus seguidores. O paradigma paraeconômico ocorre por intermédio da combinação de duas dimensões: orientação individual versus comunitária e a prescrição versus ausência de normas. A orientação individual levaria à fenonomia e a orientação comunitária levaria à isonomia. $\mathrm{O}$ cruzamento desses(as) contínuos/dimensões levaria à criação de quatro outros ambientes sociais distintos que representam diferentes comportamentos humanos, com racionalidades diversas: Economia, Motim, Isolado e Anomia, conforme esquema abaixo: 


\section{Figura 1}

\section{Paradigma Paraeconômico ou Sociedade Multicêntrica}

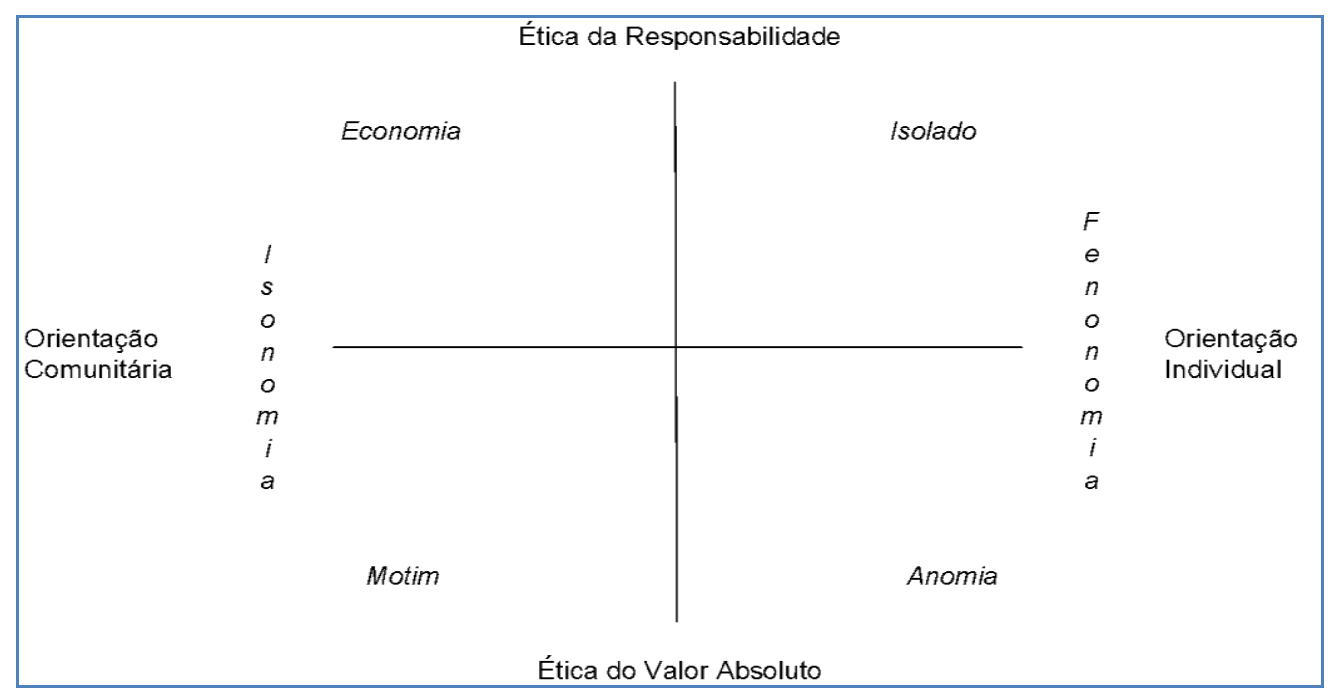

Fonte: Ramos (1989, p. 141).

Destacamos que, de acordo com o próprio Ramos, todas as categorias do modelo devem ser consideradas como elaborações heurísticas, no sentido do tipo ideal weberiano, em virtude de no mundo concreto só existirem sistemas sociais mistos. Dessa forma, podemos assim descrever os ambientes sociais:

- Economia: um contexto social altamente ordenado, estabelecido para a produção de bens e/ou para a prestação de serviços. No geral, nesse ambiente desenvolvem-se ações com foco na relação de consumo capitalista; os parâmetros são pautados em lucro e/ou na relação de custo-benefício; tendese a assumir grandes dimensões de tamanho; seus membros são detentores de empregos e são avaliados com base nesse atributo (ter e, não, ser); possui informações assimétricas entre os seus membros e o público;

- Motim: contexto de caráter coletivo desprovido de normas, cujos membros possuem pouco ou nenhum senso de ordem social. É possível que uma sociedade torne-se passível de perturbações pelos motins ao perder, para seus membros, a representatividade e o significado;

- Isonomia: contexto social em que os membros são iguais entre si, com presença mínima de normas. Dessa forma, exercem uma situação de equilíbrio entre as prescrições normativas e a atualização pessoal dos membros que compõem o sistema social. As principais características são: busca pela satisfação de cada membro com o mínimo de normas e hierarquias possíveis; basear-se numa relação de reciprocidade (dar-receber-retribuir); suas atividades são promovidas como vocação, não como emprego; sistema de tomada de decisão e de fixação de diretrizes políticas pautadas na igualdade, na participação e na democracia; existência de uma forte relação de confiança e relação interpessoal entre seus membros;

- Isolado: situação na qual o indivíduo está excessivamente comprometido com uma norma que para ele é única. No geral, esse indivíduo considera que o mundo social, como um todo, não tem sentido e forma para si um rígido sistema de crenças, vivendo num mundo totalmente particular;

- Anomia: situação em que ocorre o desaparecimento da vida pessoal e social. O indivíduo é desprovido de normas e raízes, sem compromissos com prescrições operacionais; entretanto, para garantir sua subsistência é capaz de, simultaneamente, criar o ambiente social para si próprio e obedecer às prescrições operacionais de organizações importantes; 
- Fenonomia: sistema social de caráter esporádico ou mais ou menos estável, iniciado e dirigido por um indivíduo ou por um pequeno grupo e que permite aos seus membros o máximo de opções pessoais e o mínimo de subordinação e prescrições operacionais formais (RAMOS, 1989, p. 152). Tem como características: ambiente propício à liberação da criatividade humana; alto comprometimento com as atividades desempenhadas devido a uma automotivação; embora o resultado das atividades possa ser considerado pelo mercado, os critérios econômicos são incidentais em relação às motivações dos seus membros; e, apesar do interesse em sua própria singularidade, o membro da fenonomia tem consciência social.

Fundando-se na concepção da sociedade multidimensional ou multicêntrica, Ramos chega à conclusão de que os modelos alocativos que predominam são baseados numa concepção estreita de recursos e produção, visto que, quando computam a riqueza da nação, registram apenas aquilo que é vendido e comprado mediante transações monetárias e desconsideram o não monetário como um ativo de riqueza. Segundo o autor, um fiel conceito de recursos inclui mais do que aquilo que o mercado se inclina a definir como recurso; por exemplo, as dimensões ecológicas e psíquicas - recursos que não são levados em consideração na epistemologia da economia política clássica e neoclássica. Ele ainda prossegue afirmando que "[...] há abundância de recursos e substancial capacidade produtiva que permanecem ociosas, graças à falta de esquema teórico para a organização dessas potencialidades. Do ponto de vista paraeconômico, os recursos são infinitos e não há limites ao crescimento" (RAMOS, 1989, p. 181).

Com a afirmação supramencionada, Ramos questiona o principal pressuposto da economia política quando menciona que as necessidades humanas são ilimitadas e os recursos são escassos. Numa sociedade cujo mercado não é o centro, não podemos afirmar que as necessidades humanas são ilimitadas - haja vista que os valores não estão sob o prisma da ética capitalista - nem podemos sequer considerar que os recursos são escassos. E propõe: "Para tornarem reais essas possibilidades, os indivíduos, instituições e governos precisam livrar-se dos atalhos conceituais inerentes aos modelos alocativos centrados no mercado" (RAMOS, 1989 p. 181).

Ao apresentar o seu modelo de alocação de recursos, Guerreiro Ramos avança na medida em que incorpora em suas análises outras categorias sociais não consideradas pelo modelo de alocação de recursos do mercado e do estado burguês. Com isso, revela para a Administração do Desenvolvimento o fato de que a gestão do desenvolvimento não pode ficar restrita a duas visões segmentadas, ou até mesmo opostas, de desenvolvimento: o desenvolvimentismo e o neoliberalismo. A primeira consagrou o Estado como o único agente de desenvolvimento. A segunda fez do mercado o senhor absoluto de alocação de recursos. Pela visão contemporânea, a gestão do desenvolvimento é resultado da ação administrativa de três agentes principais Estado, mercado e sociedade - bem como das relações sociais entre indivíduos, organizações e sociedades. Nesse horizonte, é possível visualizar outras possibilidades de relações sociais de produção, distribuição e consumo, de base não capitalista (economias de subsistência, economias biodiversificadas, economias solidárias, organizações autogestionárias etc.), que são alternativas ao modelo hegemônico de desenvolvimento. É nessa perspectiva que consideramos relevante o conceito de sociedade multicêntrica para o campo da Administração do Desenvolvimento, dado que vislumbra um modelo de gestão para além do econômico-mercantil.

\section{Considerações finais}

Neste ensaio, constatou-se o pioneirismo de Guerreiro Ramos em abordar, ainda na década de 1960, a relação entre gestão e desenvolvimento das nações, uma questão que só recentemente vem sendo abordada, de forma institucionalizada, pela corrente dos Estudos Críticos em Administração e pela corrente dos Estudos Críticos em Desenvolvimento. Esse pioneirismo deve-se muito à sua trajetória de vida como 
cientista social, político e gestor público, a qual lhe proporcionou experiência e conhecimento para estabelecer algumas relações entre gestão e desenvolvimento das nações.

No que se restringe à análise feita neste artigo, verificou-se, do ponto de vista epistemológico, que essa relação iniciou-se com a formulação do conceito de fato administrativo como um componente específico do fato social. Esse entendimento concedeu à administração o status de uma ciência social capaz de observar, descrever e explicar as contradições da gestão das relações sociais de produção, distribuição e consumo de uma dada sociedade. Essa interpretação proporciona a compreensão de que a ciência da Administração não se resume apenas ao processo de diagnosticar-prescrever-solucionar, ela transcende essa relação funcionalista, uma vez que é concebida como um fenômeno histórico-social. Além disso, essa relação se fortalece ainda mais, na medida em que há um aprofundamento nas categorias analíticas centrais do pensamento de Guerreiro Ramos, principalmente nas categorias razão substantiva, homem parentético e sociedade multicêntrica. Essas categorias analíticas permitiram perceber que a gestão do desenvolvimento, quer seja de uma nação, região, lugar e/ou organização, não se limita ao planejamento e ao regulamento do mercado ou do Estado. Elas evidenciaram a necessidade de outros modelos de planejamento e alocação de recursos para além das relações mercantis.

Desta maneira, entende-se que a Administração do Desenvolvimento, presente nos estudos de Guerreiro Ramos, coloca-se como um contraponto ao modelo dominante da racionalidade instrumental de alocação de recursos, pois visualiza a administração como fenômeno oriundo das relações sociais, importante para promover as mudanças necessárias à sociedade e, não, simplesmente, como um conjunto de técnicas, normas e procedimentos, tal como imaginam os ortodoxos. Ela concebe o agente administrativo como um ser capaz de tomar decisões por o prisma de uma ética de responsabilidade absoluta. Também compreende o desenvolvimento como um fenômeno social de transformação decorrente de uma possibilidade objetiva, presente entre o determinismo e a liberdade. Visualiza a gestão do desenvolvimento como algo de interesse coletivo e não apenas de especialistas e/ou organismos internacionais. Entende, também, que a gestão deve ser conduzida por um posicionamento crítico, participativo e emancipatório do indivíduo. Espera-se, diante do exposto, que o estudo possa receber as críticas e contribuições da comunidade científica quanto às questões nele refletidas, de modo a retomar os estudos sobre Administração do Desenvolvimento, um campo que necessita de mais atenção por parte da ciência da Administração.

\section{Referências}

ARRIGHI, G. Globalização e Macrossociologia histórica. Revista de Sociologia Política, v. 20, p. 13-23, 2003.

ARRIGHI, G. Adam Smith em Pequim: origens e fundamentos do século XXI. São Paulo: Boitempo, 2008.

AZEVEDO, A. A Sociologia Antropocêntrica de Alberto Guerreiro Ramos. Tese (Doutorado em Sociologia Política) - Universidade Federal de Santa Catarina, Florianópolis, 2006.

AZEVEDO, A.; ALBERNAZ, R. A "antropologia" do Guerreiro: a história do conceito de homem parentético. Cad. EBAPE.BR, Rio de Janeiro, v. 4, n. 3, p. 1-19, out. 2006.

COOKE, B. O gerenciamento do (Terceiro) Mundo. Revista de Administração de Empresas, v. 44, n. 3, p. 62-75, jul./set. 2004.

COOKE, B. Participatory management as colonial administration In: DAR, S.; COOKE, B. (Org.). The New Development Management. London e New York: Zed Books, 2008. 111-128 p.

COOKE, B.; FARIA, A. Desenvolvimento, administração e imperialismo do Atlântico Norte: para Eduardo Ibarra Colado. Cad. EBAPE. BR., v. 11, n. 2, editorial, jun. 2013. 
CUNHA, M. P. Ciência organizacional: Passado, presente futuro ou uma viagem dos clássicos aos pós-modernos. In:

CUNHA, M. P. Teoria Organizacional: Perspectivas e Prospectivas. Lisboa: Dom Quixote, 2000. 47-65 p.

DAR, S.; COOKE, B. The New Development Management. New York: Zed Bookes, 2008.

DOS SANTOS, T. Teoría de la dependencia: balance y perspectivas. México: Plaza \& Janes, 2002.

ESCOBAR, A. La invención del Tercer Mundo. Construcción y deconstrucción del desarrollo. Santafé de Bogotá: Norma, 1998 [1995]. (Capítulo 6, Visualización de uma era posdesarrollo.

ESCOBAR, A. Afteword. In: DAR, S.; COOK, B. (Orgs.). The Development Management. London-New York: Zed Books, 2008. 198-203 p.

FARIA, J. H. Consciência crítica com ciência idealista: paradoxos da redução sociológica na fenomenologia de Guerreiro Ramos. Cad. EBAPE.BR, v. 7, n. 3, p. 419-446, set. 2009.

GULRAJANI, N. The future of Development Management: examining possibilities and potential. London: Development Studies Institute, May, 2009.

KOSELLECK, R. Futuro passado: contribuição à semântica dos tempos históricos. Rio de Janeiro: Contraponto/Editora PUC-Rio, 2006.

MISOCZKY, M. C. World visions in dispute in contemporary Latin America: development x harmonic life. Organization, v. 18, n. 3, p. 345-363, 2011.

MISOCZKY, M. C.; BOHN, S. Resistindo ao desenvolvimento neoliberal: a luta do povo de Andalgalá contra o projeto megamineiros. Cad. EBAPE.BR. v. 11, n. 2, p. 311-339, jun. 2013.

RAMOS, A. G. A nova ignorância e o futuro da Administração Pública na América Latina. Rev. Adm. Pública, v. 17, n. 1, p. 32-62, jul./dez. 1970

RAMOS, A. G. Models of man and administrative theory. Public Administration Review, v. 32, n. 3, p. 241-246, May/June 1972.

RAMOS, A. G. Administração e Contexto Brasileiro: esboço de uma teoria geral da administração. 2. ed. Rio de Janeiro: FGV, 1983.

RAMOS, A. G. A Nova Ciência das Organizações: uma reconceituação da riqueza das nações. 2. ed. Rio de Janeiro: FGV, 1989.

RAMOS, A. G. A modernização em nova perspectiva: em busca do modelo de possibilidade. In: HEIDEMANN, F. G.; SALM, J. F. (Org.) Políticas públicas e desenvolvimento: bases epistemológicas e modelos de análise. Brasília-DF: Editora UnB, 2009. 41-91 p.

SANTOS, E. L.; SANTANA, W. P. Administração do Desenvolvimento: contexto, desafios e perspectivas. Revista Brasileira de Administração Política, v. 3, n. 2, p. 75-92, 2010.

SANTOS, R. S. A Administração Política como campo de conhecimento. São Paulo-Salvador: Editora Hucitec, 2004.

VIZEU, F.; MATITZ, Q. R. S. Contribuições da História dos Conceitos (Begriffsgeschichte) para os Estudos Organizacionais. In: Encontro Anual da ANPAD, 35., 2011, Rio de Janeiro. Anais... Rio de Janeiro: ANPAD, 2011.

VIZEU, F.; MENEGHETTI, F. K.; SEIFERT, R. E. Por uma crítica ao conceito de desenvolvimento sustentável. Cad. EBAPE.BR, v. 10, n. 3, p. 569-583, set. 2012. 
WALLERSTEIN, I. Globalization or the Age of Transition? A long-term view of the trajectory of the world system. International Sociology, v. 15, n. 2, p. 251-267, 2000.

WANDERLEY, S.; FARIA, A. The Chandler-Furtado case: A de-colonial re-framing of a North/South (dis) encounter. Management \& Organizational History, v. 7, n. 3, p. 219-236, 2012. 